\title{
NEW DESIGN OF MICRO-STRIP PATCH ANTENNA FOR WI-FI APPLICATIONS
}

*Ilham H. Qaddoori'

Raad H. Thaher ${ }^{1}$

\begin{abstract}
In this research, a new design of a semi-star patch antenna is simulated for Wi-Fi applications. The antenna is operated at $2.4 \mathrm{GHz}$, which is modified by inserting rectangular slots in the ground layer. Copper is used for the patch and ground layers, while FR-4 epoxy is used for the substrate layer. FR-4 epoxy has a $\mathrm{Er}=4.3$ and a loss tangent $(\tan \delta)$ of 0.025 . The antenna size is $(45 \times 48 \times 1.6) \mathrm{mm}^{3}$. The proposed antenna provides a reflection coefficient of $-41.5 \mathrm{~dB}$ and a gain of $2.8 \mathrm{~dB}$ at the operating frequency. The proposed antenna is simulated by CST STUDIO SUITE 2019.
\end{abstract}

Keywords: Micro-strip, Patch, Return loss, Wi Fi, Feedline, CST.

\section{Introduction}

In latest years, the development of communication systems has necessitated the development of antennas that are compact, high performing, light in weight, and low in cost [1]. Wireless systems include different types, such as television broadcasting, mobile communications, radar, satellite communications, landing systems, and many others, and the antenna is an essential component in these systems [2]. The general performance method of the system depends on the design of the antenna, and on the basis of the radiation of the antenna. Also, the latter is classified as anisotropic or isotropic. In wireless personal communications (WPC), reception and transmission can take place via the same antenna or via separate antennas. The antenna is a communication device that can be carried by anyone and transported from one place to another. As a result, tiny antennas conspicuous from one end without a wire connection are required. There are several uses for antennas in wireless technologies such as Wi-Fi, Wi-MAX, and GPS [3]. There are many types of antennas, such as unipolar and bipolar antennas, horn antennas, lens antennas, wide pole antennas, correction antennas, etc. Also, patch antennas include printed antennas, short correction antennas and so on. Due to the ease of printing the patch antenna on electrical circuits, it has become widely used in wireless communications [4]. The Microstripe patch antenna (MSPA) contains a dielectric substrate placed between a patch which is the radiating part and the ground plane. The patch may take many shapes, like rectangular, or circular, or a diamond. Additionally, it could have been made of a conductive material such as gold or copper. It is usual for the patch to have a feed line photo etched over the substrate [5-7]. There are multiple ways to feed MSA, including double slot feeding, line feeding, internal feeding, and experimental paired feeding [8, 9]. The size of the ground and the substrate is

*Corresponding Author: eema1035@uomustansiriyah.edu.iq 
considered larger compared to the length and width of the patch, i.e. its size, which depends on the operating frequency and the type of material used for the substrate, i.e. the dielectric constant for that material $[2,10]$. There are many related work is dealing with the MSA and its application in the different systems. Weng et al. [11] developed an MSPA $2.4 \mathrm{GHz}$ antenna using (DE) differential evolution and the antenna dimensions are $50 \mathrm{~mm}$ in length, $50 \mathrm{~mm}$ in width and 1.6 in thickness. Whereas the antenna can be used as an antenna for personal computers and routers indoors. While Nyunt [3] conducted a study on the fundamentals of the MSPA antenna and the design of a $2.4 \mathrm{GHz}$ antenna for $\mathrm{Wi}-\mathrm{Fi}$ applications. Antenna size (28.28 $\times 48.28 \times 1.6) \mathrm{mm}$ and usage of FR-4 epoxy with 4.4 dielectric constant. In [12], the designer proposed an antenna that could operate at $2.4 \mathrm{GHz}$ and $5.2 \mathrm{GHz}$ using a partial ground and a square slotted patch. As for the substrate, it is made of FR-4 material, with a dielectric constant $\left(\varepsilon_{\mathrm{r}}\right)$ of 4.6 , a length of $29 \mathrm{~mm}$, a width of $30 \mathrm{~mm}$ and a thickness of $2.4 \mathrm{~mm}$. Furthermore, the researchers suggested an MSPA antenna used for Wi-Fi applications with a frequency of $4.9 \mathrm{GHz}$ and dimensions $(24 \times 25)$ $\mathrm{mm}^{2}$ and a substrate with a thickness of $2.4 \mathrm{~mm}$ of FR-4 with a $\varepsilon_{r}$ of 4.4 [10]. Moreover, the researchers, in [13], have proposed an MSPA antenna working at a frequency of $2.4 \mathrm{GHz}$ with a large signal strength for outdoor and indoor communication and at a low cost when compared with commercial alternatives. In this research work, a new shape for the patch antenna was designed to operate at $2.4 \mathrm{GHz}$ for Wi-Fi applications.

\section{The proposed Antenna:}

The proposed antenna employs the transmission line model of an MSPA with many slots in the ground and a patch.

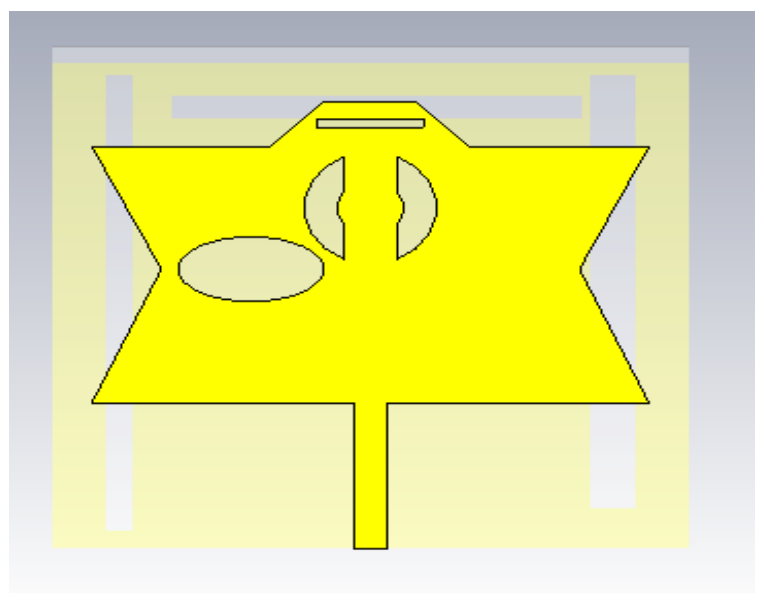

(a)

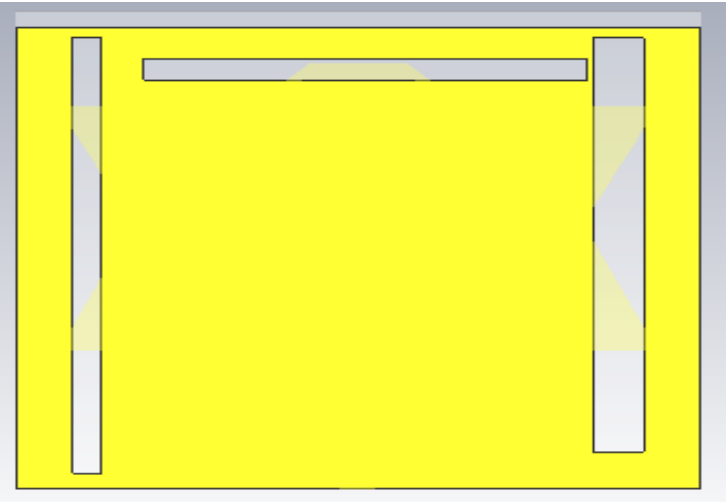

(b)

Figure 1. The suggested antenna (a) The patch and (b) the ground

The required design equations are as follows $[10,14,15]$ :

$$
f_{r}=\frac{c}{2 W \mathrm{pa}} \sqrt{\frac{2}{\left(1+\varepsilon_{r}\right)}}
$$

Where $f_{r}=$ operating frequency, $W p a=$ patch width,$\quad c=$ the light speed and $\varepsilon_{\mathrm{r}}$ is the dielectric relative constant.

And the actual length of patch $L_{p a}$ is expressed by

$$
L_{p a}=L_{e f f}-2 \Delta L
$$

$\varepsilon_{\text {reff }}$ is the effective relative dielectric constant, which is expressed by

$\varepsilon_{\text {reff }}=\frac{\left(\varepsilon_{r}+1\right)}{2}+\frac{\left(\varepsilon_{r}-1\right)}{2}[1+12 h / W \mathrm{pa}]^{-1 / 2}$ 
Length extension $(\Delta L)$ is obtain from (4)

$$
\begin{aligned}
\Delta L & =0.412 \frac{\left(\varepsilon_{\text {reff }}+0.3\right)(W p a+0.264 h)}{\left(\varepsilon_{\text {reff }}-0.258\right)(w p a * h+0.8)} \\
L_{e f f} & =\frac{c}{2 \mathrm{f}_{r} \sqrt{\varepsilon_{\text {reff }}}}
\end{aligned}
$$

$L_{e f f}$ is the effective length of rectangular patch.

$$
\begin{aligned}
& W g r=6 h+W p a \\
& L g r=6 h+L p a
\end{aligned}
$$

Where $W g r$ is the ground width, Lgr is the ground length, and $h$ is the substrate thickness. The width of the substrate (Wsu) is frequently equal to the width of the ground, and the length of the substrate (Lsu) is frequently equal to the length of the ground in most situations. There are multiple ways to feed MSA including double slot feeding, line feeding, internal feeding, and experimental paired feeding. In this work, a micro strip line feeder is used with a $Z o=50 \Omega[8,9,16]$. The proposed antenna employs the transmission line model of an MSPA with many slots in the ground. The antenna is designed on an FR-4 substrate with a thickness of $1.6 \mathrm{~mm}$, a relative dielectric constant and the size of the antenna. Table. 1 shows the parameter values after parametric study.

Table 1. The value of antenna parameters After parametric study

\begin{tabular}{lcc}
\hline MSPA Parameters & Symbol & Value in $\mathrm{mm}$ \\
Substrate width & Wsu & 48 \\
Substrate length & Lsu & 45 \\
Ground width & $W g r$ & 48 \\
Ground length & Lgr & 45 \\
Dielectric relative constant & $E r$ & 4.3
\end{tabular}

\section{Simulated Results}

The variation of return lose (S11) with frequency of the suggested antenna is seen in Figure 2 which shows that the value S11 is $41.5 \mathrm{~dB}$ at $f r=2.4 \mathrm{GHz}$. Also the real part and imaginary part of the impedance is shown in Fig. 3. The 3-D far field radiation pattern of the antenna is seen in Figure 4. The surface current distribution of suggested antenna is seen in Figure 5. And Figure $6(\mathrm{a} \& \mathrm{~b})$ shows radiation pattern of antenna at $\mathrm{f}_{r}=2.4 \mathrm{GHz}$. Figure 7 shows the variation of the gain with frequency, it is noticed that the proposed antenna gain is $2.8 \mathrm{~dB}$ at $2.4 \mathrm{GHz}$. Additionally, Figure 8 displays the group delay is $2.9 \mathrm{~ns}$ at $2.4 \mathrm{GHz}$.

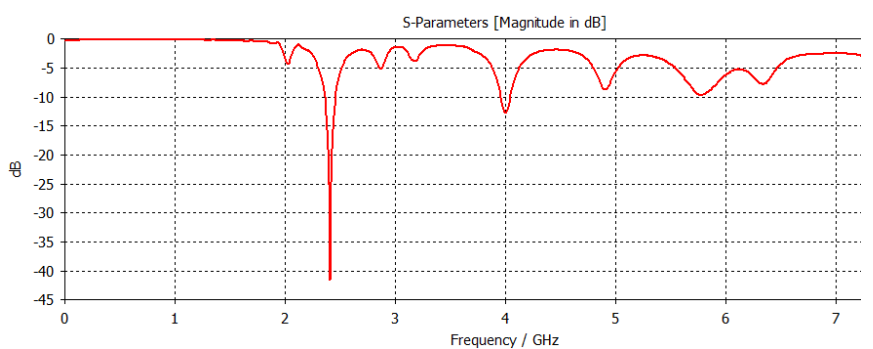

Figurer 2. Return loss (S11) with frequency

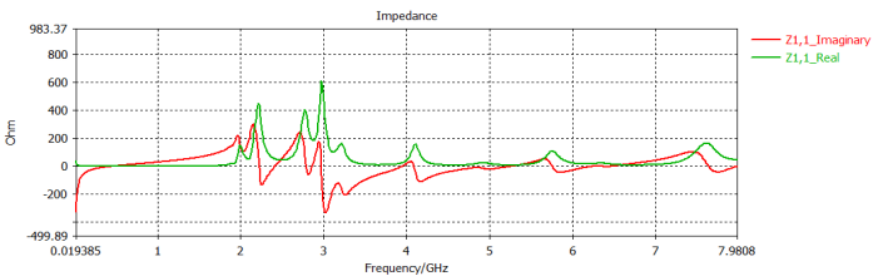

Figure 3. Impedance with frequency

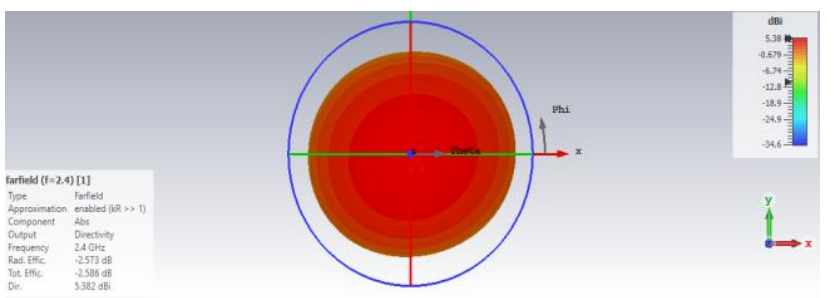

Figure 4. Far field 3-D radiation pattern of antenna

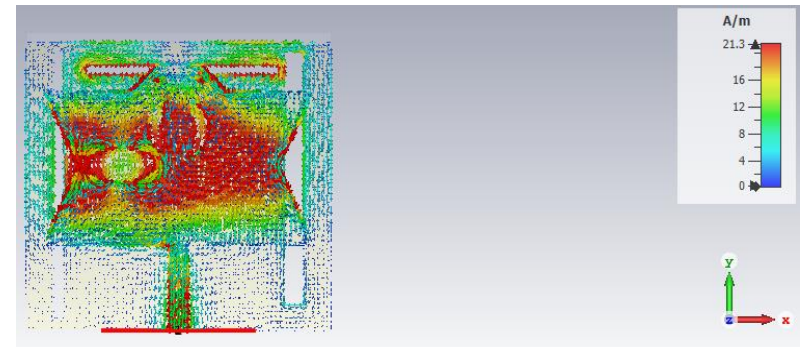

Figure 5. Surface current distribution for antenna 


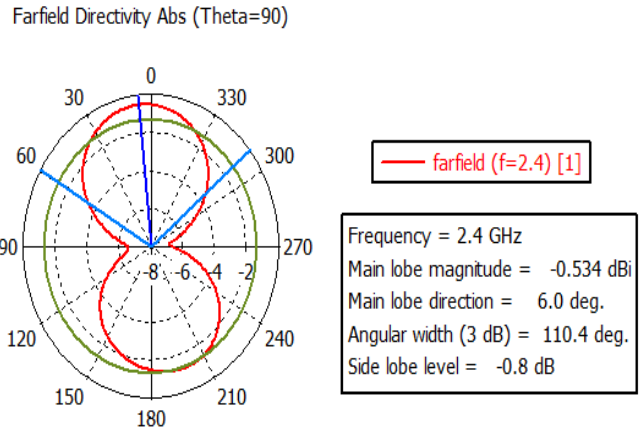

Phi / Degree vs. dBi

(a) h-field

Farfield Directivity Abs (Phi=90)

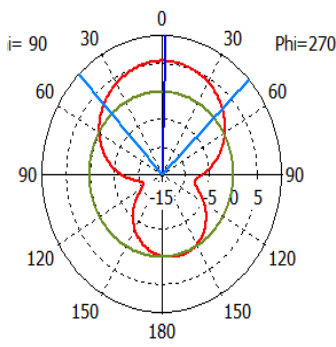

- farfield $(\mathrm{f}=2.4)[1]$

Frequency $=2.4 \mathrm{GHz}$

Main lobe magnitude $=5.39 \mathrm{dBi}$

Main lobe direction $=2.0$ deg.

Angular width $(3 \mathrm{~dB})=90.1 \mathrm{deg}$.

Side lobe level $=-5.3 \mathrm{~d}$

Theta / Degree vs. dB

(b) e-field

Figure 6. Radiation pattern of antenna

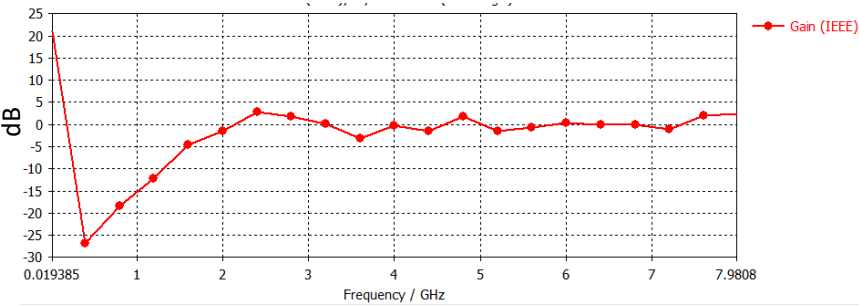

Figure 7. The Gain for proposed antenna

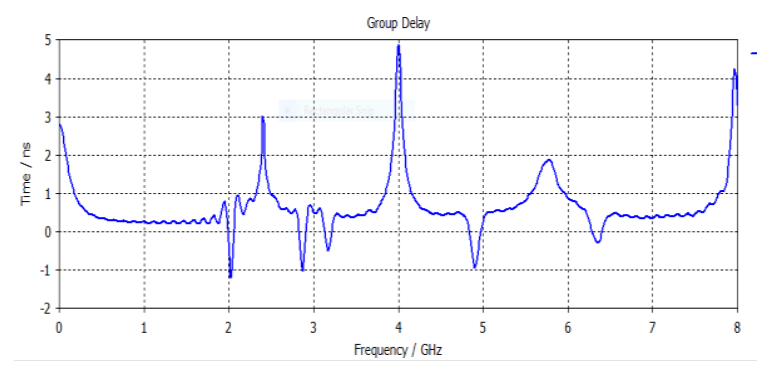

Figure 8. Group delay for proposed antenna

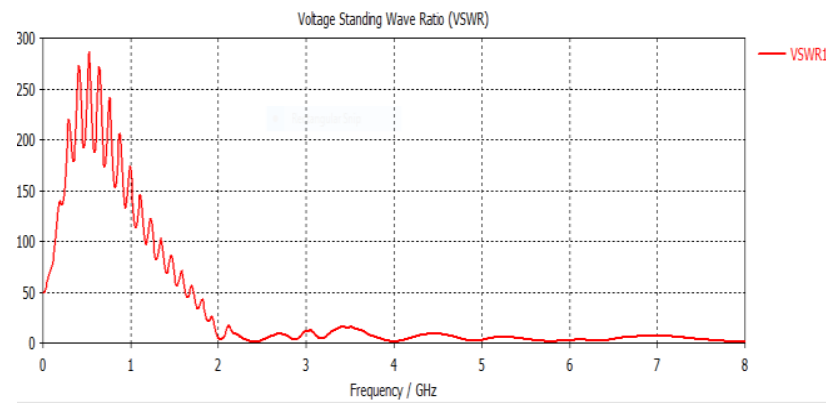

Figure 9. VSWR VS. frequency

Fig. 9 shows the relationship between the frequency and VSWR of the suggested antenna, which shows that the amount of the VSWR is 1.01 at $2.4 \mathrm{GHz}$

Table 2 illustrates the comparison with three different related works.

Table 2. Comparison with previous related works

\begin{tabular}{ccccc}
\hline References & $\begin{array}{c}\text { Dimensions } \\
\mathrm{mm} 3\end{array}$ & $\begin{array}{c}\mathrm{S} 11 \\
\mathrm{~dB}\end{array}$ & $\begin{array}{c}\text { Gain } \\
\mathrm{dB}\end{array}$ & $\begin{array}{c}\text { VSW } \\
\mathrm{R}\end{array}$ \\
Ref [3] & $\begin{array}{c}28.28 \times 48.28 \\
\mathrm{x} 1.6\end{array}$ & -31.6 & 3.42 & 1.125 \\
Ref [12] & $29 \times 30 \times 2.4$ & -26 & 2.866 & \\
Ref [10] & $24 \times 25 \times 1.6$ & -22.98 & 2.866 & 1.24 \\
$\begin{array}{c}\text { Proposed } \\
\text { antenna }\end{array}$ & $45 \times 48 \times 1.6$ & -41.5 & 2.8 & 1.016 \\
\hline
\end{tabular}

The proposed antenna has the best VSWR and S11 values, as seen in the table 2.

\section{Conclusions}

For Wi-Fi applications at the $2.4 \mathrm{GHz}$ band, a new micro strip patch antenna form has been proposed. The antenna size is (45x48x1.6) $\mathrm{mm}^{3}$ installed on FR-4 epoxy substrate with $\varepsilon r=4.3$ and $\tan \delta=0.025$. The reflection coefficient is $S 11=-41.5 \mathrm{~dB}$. The antenna is simulated by CST STUDIO SUITE 2019. As a coming work, the suggested 
antenna can be modified to include $\mathrm{Wi}-\mathrm{Fi} / \mathrm{Wi}-$ MAX applications.

\section{Acknowledgements}

The authors thank Al-Mustansiriyah University for providing the opportunity to work this research work.

\section{Conflict of interest}

The authors declare that this research dose not conflict with any other work.

\section{References}

1. Kalaimani, T. Pakiaraj, B. and Mohanamurali, R. (2015). A Compact Coplanar Feed Slotted Antenna for Wireless Applications. International Innovative Research Journal of Engineering and Technology, vol. 1, no. 2, pp. 17-20.

2. Kumar, S. and Gupta, H. (2013). Design and study of compact and wideband microstrip uslot patch antenna for Wi-Max application. IOSR Journal of Electronics and Communication Engineering IOSR-JECE, vol. 5, no. 2, pp. 45-48.

3. Nyunt, S. Z. (2018). Implementation of microstrip patch antenna for wi-fi applications. American Journal of Computer Science and Technology, vol. 1, no. 3, pp. 63-73.

4. Tecpoyotl-Torres, M. and Vera-Dimas, J. (2010). "Dual band pentagonal microstrip antenna for Wi-Fi applications". IEEE Electronics, Robotics and Automotive Mechanics Conference, pp. 255-258.

5. Thaher, R. H. and Jamil, Z. S. (2018). Design of Dual Band Microstrip Antenna for Wi-Fi and WiMax Application. TELKOMNIKA (Telecommunication Computing Electronics and Control), vol. 16, no. 6 ,pp. 2864-2870.

6. Hossain, M. B. and Hossain, M. F. (2020). "Design of a Triple Band Rectangular Slot Microstrip Patch Antenna for Wireless Applications". IEEE Region 10 Symposium (TENS YMP), pp. 1832-1835.

7. Mahfuz, M. H. Soliman, M. M. Islam, M. R. Habaebi, M. Sakib, H. N. and Malek, N. A.
(2020). "Design of UWB Microstrip Patch Antenna with Variable Band Notched Characteristic for Wi-MAX Application". IEEE Student Conference on Research and Development (SCOReD), 2020, pp. 50-54.

8. Ahmed, R. K. and Ali, I. H. (2019). " SAR Level Reduction Based on Fractal Sausage Minkowski Square Patch Antenna". JCM, vol. 14, no. 1, pp. 82-87.

9. Lal, K. N. and Singh, A. K. (2014) "Modified design of microstrip patch antenna for WiMAX communication system". Proc. of the 2014 IEEE Students' Technology Symposium, pp. 386-389.

10. Prashanth, K. V. Pavani, T. Srivatsav, N.L. Kumar, Ch. and Raja, R. (2017). Design of Inset Feed Rectangular Patch Antenna For WLAN/Wi-Fi Applications. International Journal of Pure and Applied Mathematics, vol. 116, no. 6, pp. 43-48.

11. Weng, Z. Guo, D. Wu, Y. Li, M. Hu, J. Zeng, W. Li, X. and Zeng, S. (2015). "A 2.45 $\mathrm{GHz}$ microstrip patch antenna evolved for WiFi application". IEEE Congress on Evolutionary Computation (CEC), pp. 11911195.

12. Atchay, J. S. Srinidhi, S. Yamini, P. and Venkatesh, D. (2018). Dual Band Microstrip Antenna for Wi-Fi Application. International Journal of Engineering Research \& Technology, vol. 7, no. 4, pp. 414-417.

13. Vera-Dimas, J. Tecpoyotl-Torres, M. Vargas-Chable, P. Damián-Morales, J. Escobedo-Alatorre, J. and Koshevaya, S. (2010). Individual patch antenna and antenna patch array for Wi-Fi Communication. Center for Research of Engineering and Applied Sciences (CIICAp), Autonomous University of Morelos State (UAEM), vol. 62209.

14. Ali, I. H. (2015). Design Of Microstrip Antenna Using Fractal Geometry And Metamaterial. Diyala Journal of Engineering Sciences, vol ,8 no. 2, pp. 1-17.

15. Thaher, R. H. and Jamel, Z. S. (2018). "New design of dual-band microstrip antenna for Wi-Max and WLAN applications". IEEE, in 2018 1st International Scientific Conference 
of Engineering Sciences-3rd Scientific Conference of Engineering Science (ISCES), pp. 131-134.

16. Badr, S. and Hamad, E. K. (2018). Design of multiband microstrip patch antenna for WiMax, C-band and X-band applications. Aswan Eng. J.(AswEJ), no. 4, pp. 1-7. 